\title{
Primary intestinal follicular lymphoma in a patient with very vague abdominal symptoms
}

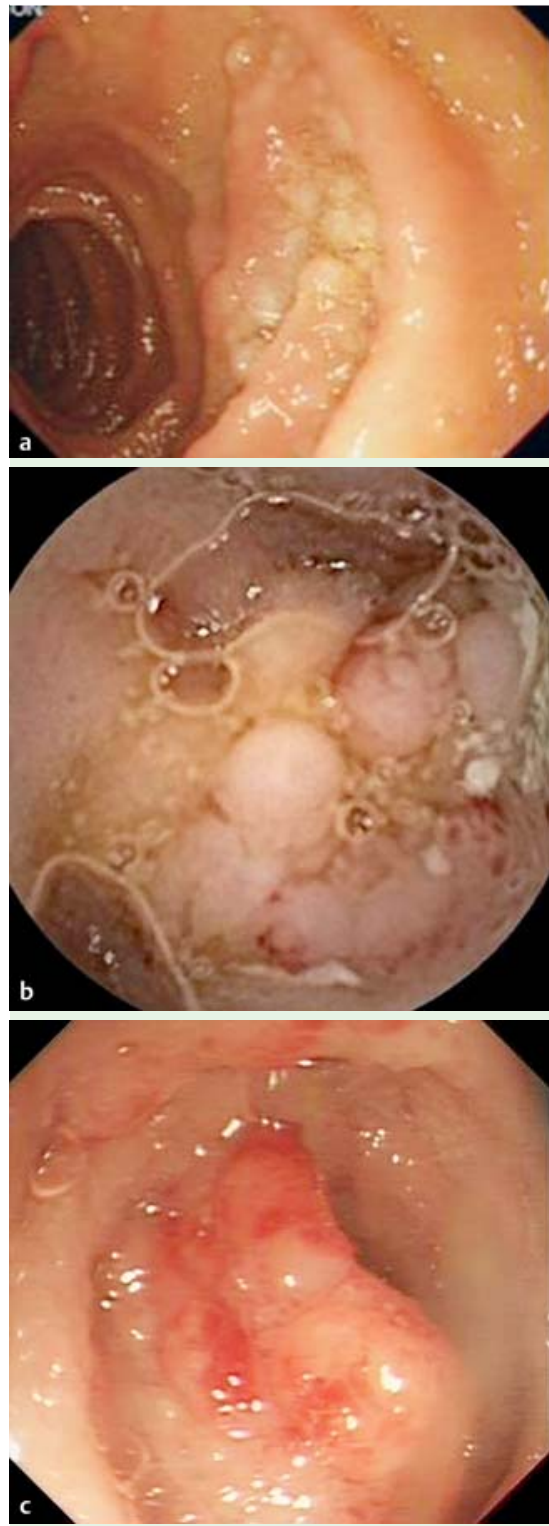

Fig. 1 Endoscopic examinations in a 50-yearold woman with vague abdominal symptoms. Colonoscopy up to the cecum had shown normal findings. a Multiple white nodules were seen in the second part of the duodenum on esophagogastroduodenoscopy (EGD).

b A small-bowel video capsule endoscopy performed after the EGD showed an abnormal nodular, erythematous area in the terminal ileum. c A repeat colonoscopy with intubation of the terminal ileum confirmed that finding, showing an erythematous area in the terminal ileum.

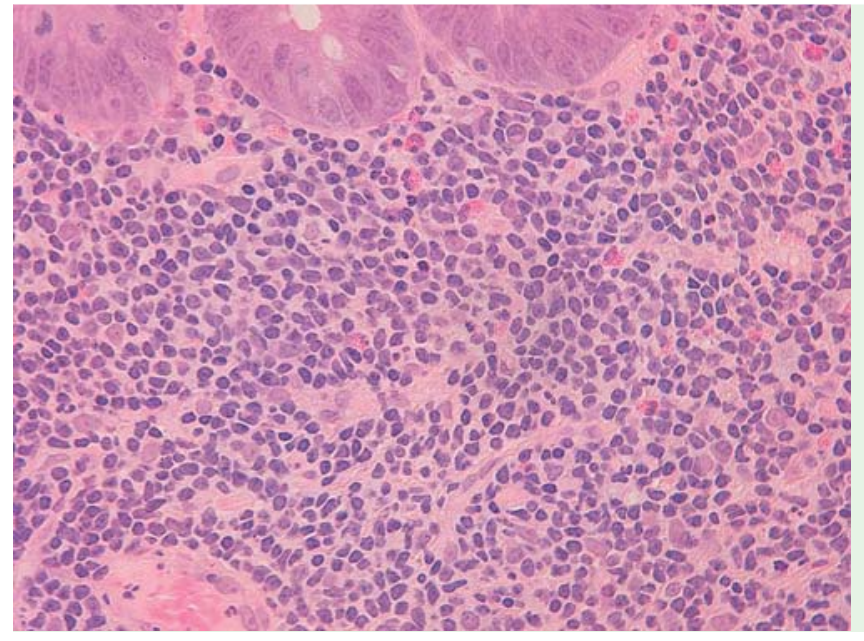

Fig. 2 Section through a duodenal biopsy (hematoxylin and eosin, $\times 400$ ), showing duodenal mucosa infiltrated with a dense lymphoid population. Proliferation of mature angular lymphoid cells is apparent (centrocytes). The MIB-1 proliferation index was $20 \%$, confirming the slow growth.

A 50-year-old female patient presented with flatulence, mild epigastric discomfort and heartburn. Medical history included nasal polyps, menorrhagia, diverticular disease and gastroesophageal reflux. There was no history of smoking, alcohol use, or weight loss.

Colonoscopy was normal up to the cecum. An esophagogastroduodenoscopy (EGD) was performed and showed a hiatus hernia and multiple small white nodules in the second part of the duodenum ( Fig.1a). Biopsies were taken. A small-bowel video capsule endoscopy (VCE) was performed following the EGD and showed a nodular area in the terminal ileum ( $\bullet$ Fig. 1 b). A repeat colonoscopy was performed to examine the terminal ileum ( $\bullet$ Fig.1c). Computed tomography of the abdomen was unremarkable. Biopsies showed infiltration with a lymphoid population with focal nodule formation. There was dense lymphocytic infiltrate in the lamina propria with follicular appearance ( Fig. 2). Staining was positive for $\mathrm{CD} 20, \mathrm{Bcl}-2$, and bcl-6, indicating a predominant B-cell population. No significant cyclin D expression and low MIB-1 positivity was noted, confirming slow growth. Primary intestinal follicular lymphoma, consistent with B-cell non-Hodgkin's lymphoma (NHL) was diagnosed.
Follicular lymphoma is the most common subtype of NHL in the Western world. Most cases are detected in the lymph nodes (nodular type), and involvement of extranodal sites usually occurs only as a result of disseminated nodal disease [1, 2]. The gastrointestinal tract is a common site of extranodal NHL, accounting for $30 \%-40 \%$ of all primary extranodal NHL. Gastrointestinal follicular lymphoma is a rare disease, with a frequency of $1 \%-$ $3 \%$ of all gastrointestinal NHL [3]. The majority of patients present with nonspecific symptoms [1]. The commonest site of presentation is the duodenum; hence, there is a role for VCE in establishing the diagnosis and evaluating the extent of the disease, although biopsies cannot be performed [4]. It is worth considering balloon-assisted enteroscopy for examination, as it allows biopsies to be taken $[4,5]$. Although gastrointestinal follicular lymphoma is rare, the number of reported cases is increasing in the Western world. Thus, awareness of primary gastrointestinal NHL should be raised, especially as endoscopic surveillance becomes more common.

\section{Endoscopy_UCTN_Code_CCL_1AC_2AC}

Competing interests: None 


\section{Fotini Debonera ${ }^{1}$, Sateesh Nagu-} mantry $^{2}$, Mo Thoufeeq ${ }^{1}$

${ }^{1}$ Department of Gastroenterology, Peterborough and Stamford Hospitals NHS Foundation Trust, Peterborough, United Kingdom

2 Department of Haematology, Peterborough and Stamford Hospitals NHS Foundation Trust, Peterborough, United Kingdom

\section{References}

1 Shia J, Teruya-Feldstein J, Pan D et al. Primary follicular lymphoma of the gastrointestinal tract: a clinical and pathologic study of 26 cases. Am J Surg Pathol 2002; 26: 216-224

2 Yoshina T, Miyake $K$, Ichimura $K$ et al. Increased incidence of follicular lymphoma in the duodenum. Am J Surg Pathol 2000; 24: $688-693$

3 Takata K, Okada H, Ohmiya $\mathrm{N}$ et al. Primary gastrointestinal follicular lymphoma involving the duodenal second portion is a distinct entity: a multicenter, retrospective analysis in Japan. Cancer Sci 2011; 102: 1532-1536

4 Nakamura M, Ohmiya N, Hirooka Y et al. Endoscopic diagnosis of follicular lymphoma with small-bowel involvement using video capsule endoscopy and double-balloon endoscopy: a case series. Endoscopy 2013; 45: $67-70$

5 van Deursen CT, Goedhard JG, Jie KS et al. Primary intestinal follicular lymphoma diagnosed by video capsule endoscopy and double-balloon enteroscopy. Endoscopy 2008; 40 (Suppl. 02): E8 - E9

\section{Bibliography}

Dol http://dx.doi.org/

10.1055/s-0034-1364942

Endoscopy 2015; 47: E139-E140

(c) Georg Thieme Verlag KG

Stuttgart · New York

ISSN 0013-726X

\section{Corresponding author}

\section{Fotini Debonera, MD}

Department of Gastroenterology

Peterborough and Stamford Hospitals,

NHS Foundation Trust

Edith Cavell Campus

Bretton Gate

Peterborough

PE3 9GZ

UK

fotini.debonera@pbh-tr.nhs.uk 